CLINICAL STUDY

\title{
Hyperthyroid levels of TSH correlate with low bone mineral density: the HUNT 2 study
}

\author{
Anders Svare ${ }^{1,2}$, Tom Ivar Lund Nilsen ${ }^{3}$, Trine Bjøro ${ }^{4,5}$, Siri Forsmo ${ }^{1}$, Berit Schei ${ }^{1}$ and Arnulf Langhammer ${ }^{1}$ \\ ${ }^{1}$ Department of Public Health and General Practice, Faculty of Medicine, Norwegian University of Science and Technology, N-7489 Trondheim, Norway, \\ ${ }^{2}$ Department of Medicine, Namsos Hospital, N-7800 Namsos, Norway, ${ }^{3}$ Human Movement Science Programme, Faculty of Social Sciences and Technology \\ Management, Norwegian University of Science and Technology, N-7489 Trondheim, Norway, ${ }^{4}$ Division of Laboratory Medicine, Department of Medical \\ Biochemistry, Rikshospitalet, Oslo University Hospital, N-0310 Oslo, Norway and ${ }^{5}$ Faculty Division Rikshospitalet, Faculty of Medicine, University of \\ Oslo, N-0310 Oslo, Norway \\ (Correspondence should be addressed to A Svare at Medical Department, Namsos Hospital; Email: anders.svare@hnt.no)
}

\begin{abstract}
Objective: To study the relationship between TSH and forearm bone mineral density (BMD) in a general female population.

Design: Cross-sectional, population-based study.

Methods: In a substudy of the Nord-Trøndelag Health Study 1995-1997 (HUNT 2), 5778 women without and 944 with self-reported thyroid disease aged $\geq 40$ years had their serum TSH and distal and ultra-distal forearm BMD measured. In range-based categories of TSH, excluding women with previous thyroid disease, a general linear model was used to calculate adjusted mean BMD, and a logistic regression model to compute adjusted odds ratio (OR) for osteopenia and osteoporosis. Corresponding models were used to compare BMD in women with self-reported hypothyroidism or hyperthyroidism to euthyroid women.

Results: In women without self-reported thyroid disease, those with TSH $<0.5 \mathrm{mU} / \mathrm{l} \mathrm{had} 10.7 \mathrm{mg} / \mathrm{cm}^{2}$ (95\% confidence interval (CI) $0.2-21.1$ ) lower distal and $9.1 \mathrm{mg} / \mathrm{cm}^{2}(95 \% \mathrm{CI}-0.7-18.9)$ lower ultra-distal BMD than women in the reference category (TSH 0.50-1.49 mU/l). No differences were found between the categories with TSH $\geq 0.50 \mathrm{mU} / \mathrm{l}$. Compared to self-reported euthyroid women, self-reported hyperthyroid women had increased odds for osteoporosis both distally (OR 1.35, 95\% CI $1.00-1.82$ ) and ultra-distally (OR $1.48,95 \%$ CI $1.10-1.99$ ).

Conclusion: Women with the lowest TSH $(<0.5 \mathrm{mU} / \mathrm{l})$ had lower forearm BMD than the reference category. No differences were observed between the TSH categories $\geq 0.50 \mathrm{mU} / \mathrm{l}$. The prevalence of osteoporosis was higher in women who reported hyperthyroidism than in women without selfreported thyroid disease.
\end{abstract}

European Journal of Endocrinology 161 779-786

\section{Introduction}

Thyroid hormones affect bone metabolism. There is an ongoing debate whether TSH or the thyroid hormones per se are responsible for these effects (1). In hyperthyroidism, there is an increased bone remodeling, with the net effect of bone resorption $(2,3)$. In accordance with this, several studies have shown overt hyperthyroidism to be a risk factor for osteoporosis (4-8). In a much cited study from 1979, the distal forearm bone mineral content was $17.5 \%$ lower in patients with hyperthyroidism than in healthy controls (6). Other studies have also shown an increased fracture risk in patients with hyperthyroidism (9-13).

Recently, two studies reported increasing bone mineral density (BMD) with increasing TSH within the reference range $(14,15)$. Furthermore, recent studies have also shown hypothyroidism to be a risk factor for fractures $(13,16,17)$. This challenges the traditional view that only hyperthyroidism is of importance in bone metabolism, and raises the hypothesis that peak BMD might be found in the upper part of the reference range, with decreased BMD and increased fracture risk below and above this level.

The aim of this study was to assess the relationship between TSH and forearm BMD, and between selfreported former or present hyper- or hypothyroidism and forearm BMD, in a population-based sample of women $\geq 40$ years.

\section{Material and methods}

\section{Study sample}

The Nord-Trøndelag Health Study 1995-97 (HUNT 2) was a comprehensive, population-based health study described in detail elsewhere (18). All participants 
answered questionnaires on a range of lifestyle and health related topics, including questions on former or current thyroid illnesses, former or current use of medication for either hypo- or hyperthyroidism, and former treatment with radioactive iodine or thyroid surgery. Standardized measurements of height and weight were conducted, and a non-fasting venous blood sample was drawn from each participant. Altogether, $66140(71.2 \%)$ of a total population of 92936 participated.

The total female population $\geq 40$ years in HUNT 2 was 23 959. Among these, three groups were assigned to forearm BMD measurement: Group 1: a 5\% random sample of all (1226 women). Group 2: a 30\% random sample aged 50-59 years restricted to the urban municipalities (1733 women). Group 3: all women were $\geq 65$ years of age ( 8787 women). The number of participants who actually underwent BMD measurement was $1029(85.9 \%), 1369(79.0 \%)$, and 4692 $(53.4 \%)$ in group 1,2 , and 3 respectively. Thus, among the 11746 women who were assigned to BMD measurement, we had BMD data on $7090(60.4 \%)$. Moreover, we excluded 368 women without information on TSH or body mass index (BMI). This left us with 6722 women available for statistical analysis.

The 5024 women who were without BMD measurement or were excluded, due to lack of information on TSH or BMI, were on average 7.3 years older than the 6722 women with data. After adjusting for age, the 5024 omitted women had higher BMI, smoked or had smoked more, had lower levels of recreational physical activity, and longer time had elapsed since menopause (data not shown).

Among the 6722 women with eligible data on the central variables, $944(14.0 \%)$ reported former or present thyroid disease or treatment; $6.8 \%$ reported hypothyroidism, 3.2\% hyperthyroidism, $4.3 \%$ goiter, $1.7 \%$ radioiodine treatment, $3.0 \%$ thyroid operations, $1.1 \%$ other thyroid diseases, $0.3 \%$ treatment with carbimazole, and $7.8 \%$ treatment with thyroxine $\left(\mathrm{T}_{4}\right)$. Subjects who had answered 'no' to the questions 'have you ever had hypothyroidism/hyperthyroidism/any other disease of the thyroid gland?' were recoded as previously hypothyroid if they reported previous $\mathrm{T}_{4}$ use, and hyperthyroid if reporting previous radioiodine- or carbimazole therapy. Those reporting both prior hypoand hyperthyroidism, or treatment consistent with both hypo- and hyperthyroidism, were classified as former hyperthyroid. This meant that, after reclassification, 424 women were classified as self-reporters of hypothyroidism and 252 of hyperthyroidism.

For the main analyses in the present study, we included the 5778 women without self-reported thyroid disease. In additional analyses, the 424 women with self-reported hypothyroidism and 252 with self-reported hyperthyroidism were also included, with the intention to study the effect of previous hypo- and hyperthyroidism on BMD. Since a TSH level within the reference range is usually rapidly obtained in the treatment of both hypo- and hyperthyroidism, and since we adjusted for current TSH, the analyses of these subgroups would mainly estimate the effect of previous disease.

\section{Blood samples}

A non-fasting venous blood sample was drawn from all participants, regardless of the time of the day. The sera were stored at $-20{ }^{\circ} \mathrm{C}$. Serum TSH was analyzed at the Hormone Laboratory, Aker University Hospital, Oslo, Norway, using a DELFIA hTSH Ultra (sensitivity $0.03 \mathrm{mU} / \mathrm{l}$ and total analytic variation $<5 \%$ ). Based on the HUNT 2 data, the TSH reference range in the present study was $0.5-3.5 \mathrm{mU} / \mathrm{l}(19)$. Free $\mathrm{T}_{4}\left(\mathrm{fT}_{4}\right)$ was measured with DELFIA $\mathrm{fT}_{4}$ (total analytical variation $<7 \%$; reference range $8-20 \mathrm{pmol} / \mathrm{l}$ ) and total triiodothyronine $\left(\mathrm{T}_{3}\right)$ with AutoDELFIA (total analytical variation $<5 \%$; reference range $1.2-2.7 \mathrm{nmol} / \mathrm{l})$. Measurement of $\mathrm{fT}_{4}$ was only done if $\mathrm{TSH}$ was $<0.2$ or $>4.0 \mathrm{mU} / \mathrm{l}$, and of $\mathrm{T}_{3}$ if $\mathrm{TSH}$ was $<0.2 \mathrm{mU} / \mathrm{l}$.

\section{Bone densitometry}

BMD was measured at the distal and ultra-distal part of the non-dominant forearm by three single-energy X-ray bone densitometers (Osteometer DTX 100, Osteometer, AS Copenhagen, Denmark). Starting from a point where the distance between the radius and the ulna was $8 \mathrm{~mm}$, the distal site was defined as $24 \mathrm{~mm}$ in the proximal direction of the ulna and radius, while the ultra-distal site was defined as the area of radius distal to this, excluding the endplate. Daily calibrations of the densitometers were performed with a phantom. All examinations were carried out in the continuous presence of specially trained technicians. In case of a previous fracture in the area of interest, the dominant arm was measured $(3.7 \%$ of the cases). If fractures were reported in both arms, the non-dominant arm was used $(0.2 \%)$.

Owing to problems with automated determination of the beginning of the radius endplate or the $8 \mathrm{~mm}$ radius/ulna distance, all the results were recalculated after manual determination of the beginning of the endplate, according to the protocol of the Tromsø Study (20).

Osteopenia and osteoporosis can be defined by calculating a s.D. score based on the distribution of BMD values. This score is termed T-score, and is defined as the individually observed BMD value minus the mean BMD for women aged 20-40 years and divided by the S.D. for women 20-40 years. In the present study, T-scores of distal and ultra-distal BMD were calculated in a random 5\% selection of women 20-40 years who participated in HUNT 2. A T-score of -1 to -2.49 is classified as osteopenia, and a $T$-score $\leq-2.5$ as osteoporosis. 


\section{Statistical analyses}

In the analyses of women without self-reported thyroid disease, we used a general linear model (GLM) to calculate mean BMD in five categories of TSH $(<0.50$, $0.50-1.49,1.50-2.49,2.50-3.50$, and $>3.50 \mathrm{mU} / \mathrm{l})$, and to estimate the crude and adjusted mean difference with 95\% confidence interval $(95 \% \mathrm{CI})$ between the categories, using TSH $0.50-1.49 \mathrm{mU} / \mathrm{l}$ as the reference category. The TSH categorization and choice of reference group were based on the laboratory's reference range and previous HUNT 2 studies (19). In order to test whether an effect of TSH was confined to subgroups, similar analyses were conducted after stratifying TSH into ten categories $(<0.1,0.1-0.49,0.5-0.99$, $1.0-1.49,1.5-1.99,2.0-2.49,2.5-2.99,3.0-3.5$, 3.51-9.99, and $\geq 10.0 \mathrm{mU} / \mathrm{l})$, and with TSH 1.0-1.49 $\mathrm{mU} / \mathrm{l}$ as the reference group. We also performed a test for trend, in which these ten TSH categories were entered as an ordinal variable in the regression model.

In a supplementary analysis, we compared women with $\mathrm{TSH}$ above the 97.5 percentile $(\mathrm{TSH} \geq 6.0 \mathrm{mU} / \mathrm{l})$ with all women who were within the reference range (considered as one group).

In a logistic regression model with either a) osteopenia or osteoporosis, or b) osteoporosis alone, as the dependent variable, we estimated adjusted odds ratios (OR) with 95\% CI within different levels of TSH compared to the reference category of TSH $0.50-1.49 \mathrm{mU} / \mathrm{l}$.

In additional analyses similar to those described above, we compared women with self-reported hypothyroidism or hyperthyroidism to euthyroid women. In a GLM, we calculated the differences in mean BMD between the groups, and in logistic regression analysis we estimated the OR for a) osteopenia or osteoporosis and b) osteoporosis alone.

All associations were adjusted for the potential confounding effect of age, BMI, recreational physical activity, smoking status, estrogen replacement therapy, and menstrual status. In the analyses of selfreported hypo- and hyperthyroid women, we also included current TSH as a potential confounder in the regression model.

For the purpose of the adjusted analyses described above, menstrual status was categorized into women still menstruating and three postmenopausal groups. Information on menstrual status and menopause was missing in $20.1 \%$, and these women were defined as menstruating if their age was $<51$ years and as menopausal if they were aged $\geq 51$ years (21). The variable 'recreational physical activity' was based on two questions on physical activity intensity and duration and categorized as no, little, moderate, and much physical activity. Information on the use of estrogen classified the women as current, former, or never users, and smokers were classified as current, former, or never smokers. For the variables recreational physical activity, estrogen use and smoking status, there were a proportion of women without information (Table 1). They were included as separate missing groups in the analyses. We had complete variable information on 2505 women.

Effect modification by both age and BMI on the association between TSH and BMD were tested including interaction terms in the models.

All statistical tests were two-sided, and all analyses were conducted using SPSS for Windows, version 15.0 (SPSS Inc., Chicago, IL, USA).

\section{Ethics}

The Norwegian Social Science Data Services and the Regional Committee for Medical Research approved the study.

\section{Results}

The characteristics of the 5778 women without selfreported thyroid disease are shown in Table 1. Osteoporosis and osteopenia were found in 30.1 and $43.8 \%$ of the women at the distal site respectively, while corresponding figures at the ultra-distal site were 26.7 and $53.7 \%$ respectively. The BMI and age increased with increasing TSH (with the exception that the TSH $<0.50 \mathrm{mU} / \mathrm{l}$ group was older than the $0.50-1.49$ and $1.50-2.49 \mathrm{mU} / \mathrm{l}$ groups), whereas the

Table 1 Basic characteristics of the study population of women aged $\geq 40$ years without self-reported thyroid disease.

\begin{tabular}{lcr}
\hline Variables & $\boldsymbol{n}$ & Mean (s.D.) \\
\hline Age (years) & 5778 & $66.6(11.5)$ \\
Body mass index $\left(\mathrm{kg} / \mathrm{m}^{2}\right)$ & 5778 & $27.1(4.4)$ \\
\hline & $\boldsymbol{n}$ & $\%$ \\
\hline Smoking & & \\
Current & 1385 & 24.0 \\
Former & 735 & 12.7 \\
Never & 2306 & 39.9 \\
Unknown & 1352 & 23.4 \\
Menstruation & & \\
Still menstruating & 659 & 11.4 \\
Menopause <5 years ago & 379 & 6.6 \\
Menopause 5-9 years ago & 328 & 5.7 \\
Menopause $>9$ years ago & 3249 & 56.2 \\
Unknown & 1163 & 20.1 \\
Recreational physical activity & & \\
No & 1065 & 18.4 \\
Little & 1930 & 33.4 \\
Moderate & 884 & 15.3 \\
Much & 396 & 6.9 \\
Unknown & 1503 & 26.0 \\
Estrogen use & & \\
Current & 535 & 9.3 \\
Former & 232 & 4.0 \\
Never & 3081 & 53.3 \\
Unknown & 1930 & 33.4 \\
\hline
\end{tabular}


Table 2 TSH in relation to bone mineral density (BMD) in 5778 women aged $\geq 40$ years without self-reported thyroid disease.

\begin{tabular}{|c|c|c|c|c|c|c|c|}
\hline \multirow[b]{2}{*}{ TSH (mU/l) } & \multirow[b]{2}{*}{$n$} & \multicolumn{3}{|c|}{ BMD at distal site $\left(\mathrm{mg} / \mathrm{cm}^{2}\right)$} & \multicolumn{3}{|c|}{ BMD at ultra-distal site $\left(\mathrm{mg} / \mathrm{cm}^{2}\right)$} \\
\hline & & Mean & $\begin{array}{l}\text { Crude } \\
\text { difference }\end{array}$ & $\begin{array}{c}\text { Adjusted }{ }^{\mathrm{a}} \text { difference } \\
(95 \% \mathrm{Cl})\end{array}$ & Mean & $\begin{array}{l}\text { Crude } \\
\text { difference }\end{array}$ & $\begin{array}{c}\text { Adjusted }^{\mathrm{a}} \text { difference } \\
(95 \% \mathrm{Cl})\end{array}$ \\
\hline$<0.50$ & 136 & 390.8 & -22.1 & $-10.6(-21.1,-0.2)$ & 303.6 & -19.6 & $-9.1(-18.9,0.7)$ \\
\hline $0.50-1.49$ & 2188 & 412.9 & 0.0 & 0.0 (reference) & 323.2 & 0.0 & 0.0 (reference) \\
\hline $1.50-2.49$ & 2110 & 408.7 & -4.2 & $0.8(-2.8,4.4)$ & 319.9 & -3.3 & $1.3(-2.1,4.7)$ \\
\hline $2.50-3.50$ & 802 & 405.7 & -7.2 & $2.6(-2.3,7.5)$ & 315.4 & -7.8 & $0.7(-3.9,5.3)$ \\
\hline$>3.50$ & 542 & 400.5 & -12.4 & $2.3(-3.4,8.0)$ & 310.1 & -13.1 & $0.7(-4.7,6.1)$ \\
\hline
\end{tabular}

$\mathrm{Cl}$, confidence interval.

${ }^{a}$ Adjusted for age, body mass index, recreational physical activity, smoking status, estrogen use, and menstrual status.

numbers of smokers and ex-smokers decreased. For the other covariables, no obvious patterns emerged. This means that the differences between the unadjusted and adjusted estimates in Tables $2-5$ were mainly caused by these three covariables.

In analysis of women without self-reported thyroid disease and with TSH classified into five categories, those with TSH $\leq 0.50 \mathrm{mU} / \mathrm{l}$ had $10.7 \mathrm{mg} / \mathrm{cm}^{2}(95 \% \mathrm{CI}$, $0.2-21.1)$ lower adjusted distal BMD and $9.1 \mathrm{mg} / \mathrm{cm}^{2}$ (95\% CI, - 0.7-18.9) lower adjusted ultra-distal BMD compared to the reference group of women with TSH 0.5-1.49 mU/l (Table 2). No statistically significant differences in BMD were found between the reference group and the higher TSH categories.

Figure 1 shows the adjusted mean distal and ultradistal BMD across ten categories of TSH. At the distal site, the TSH $<0.10 \mathrm{mU} / \mathrm{l}$ group had statistically significantly lower adjusted BMD than all the other groups $(P<0.05)$. Ultra-distally, the TSH $<0.10 \mathrm{mU} / \mathrm{l}$ group had statistically significantly lower BMD compared to all groups $(P<0.05)$, except the $0.10-0.49 \mathrm{mU} / \mathrm{l}$ group $(P=0.151)$. Compared to women with TSH $1.0-1.49 \mathrm{mU} / \mathrm{l}$, those with
$\mathrm{TSH}<0.10 \mathrm{mU} / \mathrm{l}$ had $35.9 \mathrm{mg} / \mathrm{cm}^{2}(95 \%$ CI, $16.5-$ $55.3)$ lower adjusted distal and $21.1 \mathrm{mg} / \mathrm{cm}^{2}(95 \% \mathrm{CI}$, 2.9-39.4) lower adjusted ultra-distal BMD. The mean (s.D.) $\mathrm{fT}_{4}$ and $\mathrm{T}_{3}$ in the $\mathrm{TSH}<0.10 \mathrm{mU} / \mathrm{l}$ group were 20.9 (10.6) pmol/l and 3.0 (1.1) nmol/l respectively, indicating that many of the women in this group had clinically overt hyperthyroidism. At both the distal and ultra-distal site, the $0.10-0.49 \mathrm{mU} / \mathrm{l}$ TSH group had slightly lower adjusted BMD than the higher TSH groups, but no statistically significant differences were seen. The test for trend gave a $P$ value of 0.07 for the distal and 0.24 for the ultra-distal site.

When we compared women with TSH above the 97.5 percentile with all women within the reference range (considered as one group), the groups had similar adjusted mean BMDs, both at the distal and ultra-distal site (data not shown).

No statistically significant differences in the prevalence of either the combination of osteopenia or osteoporosis nor osteoporosis alone were found between the reference category with TSH $0.50-1.49 \mathrm{mU} / \mathrm{l}$ and the other TSH categories in the adjusted analyses. However, a non-significant pattern of more osteoporosis

Table 3 Odds ratio (OR) for either osteopenia or osteoporosis combined or for osteoporosis assessed from bone mineral density (BMD) measures at the distal or ultra-distal forearm, associated with TSH in 5778 women aged $\geq 40$ years without self-reported thyroid disease.

\begin{tabular}{|c|c|c|c|c|c|c|c|c|}
\hline \multirow[b]{2}{*}{ TSH (mU/l) } & \multicolumn{4}{|c|}{ Osteopenia or osteoporosis combined ${ }^{a}$} & \multicolumn{4}{|c|}{ Osteoporosis $^{b}$} \\
\hline & Non-cases & Cases & $\mathrm{OR}^{\mathrm{c}}$ & $\mathrm{OR}^{\mathrm{d}}(95 \% \mathrm{Cl})$ & Non-cases & Cases & $\mathrm{OR}^{\mathrm{c}}$ & $\mathrm{OR}^{\mathrm{d}}(95 \% \mathrm{Cl})$ \\
\hline \multicolumn{9}{|c|}{ Distal forearm BMD measures } \\
\hline$<0.50$ & 27 & 109 & 1.65 & $1.51(0.90,2.53)$ & 82 & 54 & 1.62 & $1.35(0.87,2.09)$ \\
\hline $0.50-1.49$ & 633 & 1555 & 1.00 & 1.00 (reference) & 1551 & 637 & 1.00 & 1.00 (reference) \\
\hline $1.50-2.49$ & 529 & 1581 & 1.21 & $1.08(0.91,1.27)$ & 1503 & 607 & 0.98 & $0.86(0.74,1.00)$ \\
\hline $2.50-3.50$ & 197 & 605 & 1.25 & $0.95(0.76,1.19)$ & 554 & 248 & 1.10 & $0.86(0.70,1.06)$ \\
\hline$>3.50$ & 124 & 418 & 1.38 & $0.88(0.67,1.15)$ & 360 & 182 & 1.24 & $0.93(0.74,1.17)$ \\
\hline \multicolumn{9}{|c|}{ Ultra-distal forearm BMD measures } \\
\hline$<0.50$ & 21 & 115 & 1.55 & $1.35(0.77,2.35)$ & 91 & 45 & 1.46 & $1.14(0.74,1.77)$ \\
\hline $0.50-1.49$ & 482 & 1708 & 1.00 & 1.00 (reference) & 1628 & 562 & 1.00 & 1.00 (reference) \\
\hline $1.50-2.49$ & 411 & 1698 & 1.16 & $1.02(0.85,1.22)$ & 1567 & 542 & 0.94 & $0.90(0.77,1.06)$ \\
\hline $2.50-3.50$ & 131 & 670 & 1.44 & $1.18(0.91,1.53)$ & 577 & 224 & 1.13 & $0.94(0.76,1.16)$ \\
\hline$>3.50$ & 87 & 455 & 1.48 & $0.97(0.72,1.30)$ & 374 & 168 & 1.31 & $1.03(0.82,1.30)$ \\
\hline
\end{tabular}

$\mathrm{Cl}$, confidence interval.

a Osteopenia or osteoporosis defined as a $T$-score $\leq-1.0$ based on BMD measures.

${ }^{b}$ Osteoporosis defined as a $T$-score $\leq-2.5$ based on BMD measures.

${ }^{\mathrm{c}}$ Crude OR.

${ }^{\mathrm{d} O R}$ adjusted for age, body mass index, recreational physical activity, smoking status, estrogen use, and menstrual status. 
Table 4 Self-reported hypo- and hyperthyroidism in relation to distal and ultra-distal forearm bone mineral density (BMD) in 6454 women aged $\geq 40$ years.

\begin{tabular}{|c|c|c|c|c|c|c|c|}
\hline \multirow[b]{2}{*}{$\begin{array}{l}\text { Thyroid } \\
\text { status }\end{array}$} & \multirow[b]{2}{*}{$n$} & \multicolumn{3}{|c|}{ BMD at distal site $\left(\mathrm{mg} / \mathrm{cm}^{2}\right)$} & \multicolumn{3}{|c|}{ BMD at ultra-distal site $\left(\mathrm{mg} / \mathrm{cm}^{2}\right)$} \\
\hline & & Mean & $\begin{array}{l}\text { Crude } \\
\text { difference }\end{array}$ & $\begin{array}{c}\text { Adjusted }{ }^{a} \text { difference } \\
(95 \% \mathrm{Cl})\end{array}$ & Mean & $\begin{array}{l}\text { Crude } \\
\text { difference }\end{array}$ & $\begin{array}{c}\text { Adjusted }{ }^{\mathrm{a}} \text { difference } \\
(95 \% \mathrm{Cl})\end{array}$ \\
\hline Euthyroid & 5778 & 408.5 & 0.0 & 0.0 (reference) & 318.9 & 0.0 & 0.0 (reference) \\
\hline Hyperthyroid & 252 & 390.6 & -17.9 & $-4.5(-12.4,3.4)$ & 302.9 & -16.0 & $-3.3(-10.7,4.1)$ \\
\hline Hypothyroid & 424 & 405.6 & -2.9 & $2.8(-3.5,9.2)$ & 314.3 & -4.6 & $1.2(-4.8,7.1)$ \\
\hline
\end{tabular}

$\mathrm{Cl}$, confidence interval.

${ }^{a}$ Adjusted for age, body mass index, recreational physical activity, smoking status, estrogen use, menstrual status, and measured level of TSH.

and osteopenia was found in the TSH $<0.50 \mathrm{mU} / \mathrm{l}$ category (Table 3).

In additional analysis comparing mean BMD in women with self-reported hypo- or hyperthyroidism to those who were euthyroid, there was a tendency towards lower BMD in the hyperthyroid group, but no statistically significant differences (Table 4). When studying the prevalence of osteoporosis, we found that women with self-reported hyperthyroidism had an adjusted OR of 1.48 (95\% CI 1.10-1.99) at the ultradistal and 1.35 (95\% CI 1.00-1.82) at the distal site compared to euthyroid women (Table 5). No statistically significant associations were found in the analyses where the combination of osteopenia and osteoporosis was used instead of osteoporosis.

There were no modifying effects of either BMI or age on the association between TSH and BMD, and corresponding stratifications were not necessary.

\section{Discussion}

This large population-based cross-sectional study of women aged $\geq 40$ years showed that TSH $<0.50 \mathrm{mU} / \mathrm{l}$ was associated with a lower distal forearm BMD than the reference category with TSH $0.50-1.49 \mathrm{mU} / \mathrm{l}$. The lower BMD was most prominent for women with TSH $<0.10 \mathrm{mU} / \mathrm{l}$. For women with TSH levels $\geq 0.5 \mathrm{mU} / \mathrm{l}$, no differences in BMD were seen. The pattern was the same ultra-distally, although fewer comparisons reached statistical significance. Furthermore, compared to euthyroid women, self-reported hyperthyroidism was associated with a statistically significant increased risk for osteoporosis at the ultradistal site, and a close to statistically significant increased risk at the distal site.

This study is the largest one in a general female population on the relationship between TSH and BMD. The strength of the study is the number of participants and the population-based design. The numbers of participants were unequally distributed by age, but we have no indications that this should bias our results.

TSH levels vary biologically throughout the day, and are also influenced by exogenous factors like exercise and sleep deprivation (22). Our blood samples were drawn at any time during daytime and without considering external factors. This might have added non-differential bias to the study that could have weakened the observed associations.

For all covariates there were women with missing information. Only about $43 \%$ had complete data on all covariables. For menstrual status, age made us able to categorize them with relatively low risk for misclassification. For recreational physical activity, smoking status and estrogen use, those with missing information were included as separate categories. This might add

Table 5 Odds ratio (OR) for either osteopenia or osteoporosis combined ${ }^{a}$ or for osteoporosis ${ }^{b}$ assessed from bone mineral density (BMD) measures at the distal or ultra-distal forearm, associated with self-reported hypo- and hyperthyroidism in 6454 women aged $\geq 40$ years.

\begin{tabular}{|c|c|c|c|c|c|}
\hline \multirow[b]{2}{*}{ Thyroid status } & \multicolumn{3}{|c|}{ Osteopenia or osteoporosis combined ${ }^{a}$} & \multicolumn{2}{|c|}{ Osteoporosis $^{b}$} \\
\hline & $n$ & $\mathrm{OR}^{\mathrm{c}}$ & $\mathrm{OR}^{\mathrm{d}}(95 \% \mathrm{Cl})$ & $\mathrm{OR}^{\mathrm{c}}$ & $\mathrm{OR}^{\mathrm{d}}(95 \% \mathrm{Cl})$ \\
\hline \multicolumn{6}{|c|}{ Distal forearm BMD measures } \\
\hline Euthyroid & 5778 & 1.00 & 1.00 (reference) & 1.00 & 1.00 (reference) \\
\hline Hyperthyroid & 252 & 1.34 & $0.96(0.67,1.38)$ & 1.56 & $1.35(1.00,1.82)$ \\
\hline Hypothyroid & 424 & 1.07 & $0.91(0.69,1.20)$ & 1.10 & $1.02(0.79,1.30)$ \\
\hline \multicolumn{6}{|c|}{ Ultra-distal forearm BMD measures } \\
\hline Euthyroid & 5778 & 1.00 & 1.00 (reference) & 1.00 & 1.00 (reference) \\
\hline Hyperthyroid & 252 & 1.32 & $0.90(0.60,1.35)$ & 1.68 & $1.48(1.10,1.99)$ \\
\hline Hypothyroid & 424 & 1.07 & $0.87(0.65,1.18)$ & 1.09 & $1.01(0.79,1.30)$ \\
\hline
\end{tabular}

$\mathrm{Cl}$, confidence interval.

${ }^{a}$ Osteopenia or osteoporosis defined as a $T$-score $\leq-1.0$ based on BMD measures.

'Osteoporosis defined as a $T$-score $\leq-2.5$ based on BMD measures.

${ }^{\mathrm{c}}$ Crude OR.

${ }^{\mathrm{d} O R}$ adjusted for age, body mass index, recreational physical activity, smoking status, estrogen use, menstrual status, and measured level of TSH. 


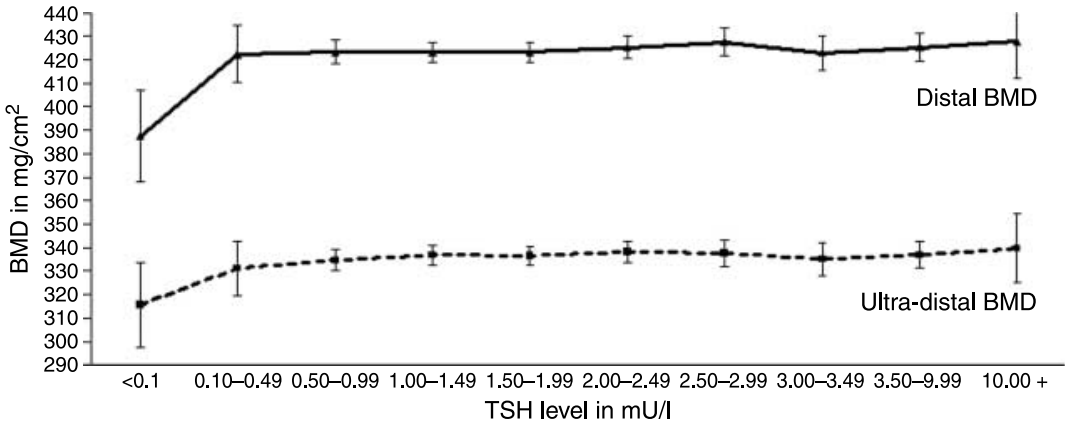

Figure 1 Distal and ultra-distal forearm bone mineral density (BMD) in $\mathrm{mg} / \mathrm{cm}^{2}$ with $95 \% \mathrm{Cl}$ by TSH levels: adjusted for age, body mass index, recreational physical activity, smoking status, estrogen use, and menstrual status. residual confounding, but sensitivity analyses revealed consistent results.

Among women $\geq 65$ years, only $53.4 \%$ had bone densitometry measurements. In the five urban municipalities, bone densitometry was performed at the same time as the rest of the screening examinations, while in the rural municipalities this examination was performed 6-8 weeks after the screening. This, in addition to longer distances to the measurement stations in the rural municipalities, mainly explains lower participation rate among those $\geq 65$ years. There is, however, no reason to believe that there should be different relations between TSH and BMD by municipality.

Categorization of women as former hypo- or hyperthyroid, partly according to answers on use of medication or treatment, may have lead to misclassifications. $\mathrm{T}_{4}$ is sometimes used to treat goiter and radioiodine in the treatment of thyroid cancer. Even so, the use of such treatments in these settings is quite rare, and it is not likely that this would have distorted our results.

For measurement of BMD, the hip and the lumbar spine are the commonly preferred sites. In the present study, we have based our classification of osteoporosis and osteopenia on $T$-scores calculated from forearm BMD measurements. For middle-aged women, measurements in the forearm are likely to overestimate the prevalence of osteoporosis, compared to measurements at the hip and spine (23). Thus, a T-score threshold of $\leq-2.5$ to define osteoporosis has been recommended only when hip measurements are used (24). Nevertheless, it is not likely that this misclassification is differential between the TSH categories.

Hyperthyroidism affects cortical more than trabecular bone, and forearm measurements are recognized and well suited for studying the effect of thyroid hormones on bones (3). In accordance with this, we also found a stronger association between TSH and BMD at the distal (mainly cortical bone) than ultradistal site (mainly trabecular bone).

The detrimental effect of hyperthyroidism on the skeleton has been known since 1891 (25). Traditionally, this has been considered a direct effect of the thyroid hormones. Recent research has challenged this view, indicating an independent bone protective role for TSH (1). TSH receptors have been found on both osteoclast and osteoblast precursor cells (26).
Treatment with TSH has been shown to have an antiresorptive effect, as measured on blood and urine bone markers, and to have a beneficial effect on BMD in animals (27-29). Tumour necrosis factor- $\alpha$ has been suggested to mediate the effect of TSH on bone (30). In 2008, a cross-sectional Dutch population study in patients with former thyroid carcinomas found TSH to be independently inversely correlated to markers of both bone resorption and formation (31).

Whether subclinical hyperthyroidism has the same impact as overt hyperthyroidism is controversial. Inherent problems are that different hormone levels have been used in definitions, and that both exogenously and endogenously subclinical hyperthyroidism have been studied (32). Since we only had data on $\mathrm{fT}_{4}$ and $\mathrm{T}_{3}$ in subpopulations, we could not analyze the data according to formal criteria for the subclinical conditions. Instead we studied the TSH $0.10-0.49 \mathrm{mU} / \mathrm{l}$ subgroup separately. Our results suggest that women with a slightly subnormal TSH have a BMD between those with lower and higher TSH (Fig. 1). However, the differences did not reach statistical significance, which may be due to lack of statistical power after subdivisions.

Many recent studies have addressed the relationship between TSH and BMD. Two cross-sectional studies focused especially on different TSH strata within the reference range. A hospital-based study from South Korea found an increasing hip and lumbar BMD with increasing TSH from the subclinical level to the high normal TSH level (14). Comparing quintiles within the normal range, the highest quintile $(2.8-5.0 \mathrm{mU} / \mathrm{l})$ had significantly higher BMD than the lowest quintile $(0.5-1.1 \mathrm{mU} / \mathrm{l})$. Based on the National Health and Nutrition Examination Survey III (NHANES III) data, Martha S Morris studied the association between normal range TSH-strata and hip BMD in postmenopausal women (15). Dividing the participants dichotomously based on mean TSH, she found that the low TSH group (0.39-1.79 mU/l) had higher risk for osteopenia and osteoporosis than the high TSH $(1.8-4.6 \mathrm{mU} / \mathrm{l})$ group. Furthermore, a regression analysis confirmed a positive relation between BMD and TSH quintiles within the normal range.

Another South Korean study found that both subclinical hypo- and hyperthyroidism were associated with reduced femoral neck BMD, as compared to 
euthyroid women (33). In a recent population-based study from Tromsø in Norway, the higher $2.5 \%$ female TSH group ( $>4.56 \mathrm{mU} / \mathrm{l}$ group) had statistically significantly higher femoral neck BMD than euthyroid women (34). In the Tromsø study, within the normal TSH range, no relationship between TSH and BMD was seen. In recent years, population-based studies have also shown a relationship between hypothyroidism and increased fracture risk $(13,16,17)$.

In the present study, no statistically significant differences in BMD were found if TSH was within or above the reference range. We consider this our single most important finding. Neither could we reproduce the effect on BMD among women with TSH above the 97.5 percentile that was reported from the Tromsø study (34). Instead, our study showed a threshold BMD in the low-normal TSH range, above which the BMD remained stable. This suggests that differences in BMD based on TSH, with the exception for low TSH, are of minor clinical importance.

As described above, our results concerning TSH within the normal range is contradictory to the findings of two recent epidemiologic studies, but in agreement with the findings of the Tromsø study $(14,15,34)$. One reason might be that our study (and most of the results from the Tromsø study) was based on forearm BMD measurements, whereas the other studies used hip and lumbar spine measurements. Other differences between the studies were different populations, different subject inclusion and exclusion criteria, and different covariables.

One possible explanation for the previously reported association between hypothyroidism and fractures, if this proves to be a reproducible finding, might be increased extra-skeletal morbidity in hypothyroidism, for example falls. Another explanation could be that hypothyroidism has a detrimental influence on bone quality without corresponding effect on demineralization, like what is found in excess of glucocorticosteroids.

There is controversy on whether the patients treated for hyperthyroidism fully regain their BMD loss. Some longitudinal studies have shown only partial recovery in $\operatorname{BMD}(6,35,36)$. In accordance with this, in a large case-control study, former hyperthyroidism was associated with an increased fracture risk for 5 years following the hyperthyroidism diagnosis (17). On the contrary, two Danish studies from 1996 found no difference in BMD between previously treated hyperthyroid patients and controls $(37,38)$. The latter studies were performed after at least 4 and 6 years of euthyroidism respectively. The results from the present study fit the hypothesis that former hyperthyroidism is a risk factor for low BMD. However, our data on selfreported hyperthyroidism could not differentiate between present or previous hyperthyroidism or estimate the duration of euthyroidism after treatment. We did try to adjust for these factors by adding current TSH as a covariable. Additionally, as explained above, defining hyperthyroidism on the basis of treatment consistent with hyperthyroidism may have lead to some misclassification. Therefore, based on the present study, conclusions on the relationship between former hyperthyroidism and BMD should be drawn with caution.

According to Marshall et al. one s.D. reduction in distal radius $\mathrm{BMD}$ is associated with an increased risk for forearm and vertebral fractures of 1.7 and hip fracture of 1.8 (39). Based on the distal forearm results of the present study, this means that those with TSH $<0.50 \mathrm{mU} / \mathrm{l}$, compared to the $0.50-1.49 \mathrm{mU} / \mathrm{l}$ group, would have about $8 \%$ higher fracture risk. For those with TSH $<0.1 \mathrm{mU} / \mathrm{l}$, compared to the TSH $1.0-1.49 \mathrm{mU} / \mathrm{l}$ group, the fracture risk would be about $31 \%$ higher.

In conclusion, no association was found between TSH within and above the reference range and forearm BMD. Subnormal TSH was associated with a decreased BMD, especially prominent in the TSH $<0.10 \mathrm{mU} / \mathrm{l}$ group. Self-reported hyperthyroid women had an increased prevalence of osteoporosis.

\section{Declaration of interest}

We declare that we do not have any conflict of interest.

\section{Funding}

The Hormone Laboratory, Aker University Hospital, Oslo, did the TSH, $\mathrm{fT}_{4}$ and $\mathrm{T}_{3}$ analyses, with some financial support from Wallac $\mathrm{Oy}$, Turku, Finland. This work was supported by Health Nord-Trøndelag (grant number 2, 2005); and the Norwegian Foundation for Health and Rehabilitation (grant number 0238, 2008).

\section{Author contribution statement}

Contributors: A Svare conceived the idea, designed the study, did the analyses, and wrote the paper. T I L Nilsen participated in the statistical analyses and interpretation of the results, and contributed in writing the paper. T Bjøro designed the study, interpreted the results, and contributed in writing the paper. S Forsmo and B Schei interpreted the results and contributed in writing the paper. A Langhammer designed the study, was responsible for bone densitometry, quality assurance of BMD and questionnaire data, interpreted the results, and contributed in writing the paper.

\section{Acknowledgements}

The HUNT Research Center provided the data. The HUNT study is a collaboration between HUNT Research Centre, Faculty of Medicine, Norwegian University of Science and Technology, Norwegian Institute of Public Health, and Nord-Trøndelag County Council.

\section{References}

1 Galliford TM, Murphy E, Williams AJ, Bassett JHD \& Williams GR. Effects of thyroid status on bone metabolism: a primary role for thyroid stimulating hormone or thyroid hormone? Minerva Endocrinologica 200530 237-246.

2 Cooper DS. Hyperthyroidism. Lancet 2003362 459-468.

3 Greenspan SL \& Greenspan FS. The effect of thyroid hormone on skeletal integrity. Annals of Internal Medicine 1999130 750-758. 
4 Fraser SA, Anderson JB, Smith DA \& Wilson GM. Osteoporosis and fractures following thyrotoxicosis. Lancet 1971 1 981-983.

5 Linde J \& Friis T. Osteoporosis in hyperthyroidism estimated by photon absorptiometry. Acta Endocrinologica 197991 437-448.

6 Toh SH, Claunch BC \& Brown PH. Effect of hyperthyroidism and its treatment on bone mineral content. Archives of Internal Medicine $1985145883-886$.

7 Ben-Shlomo A, Hagag P, Evans S \& Weiss M. Early postmenopausal bone loss in hyperthyroidism. Maturitas 200139 19-27.

8 Udaykumar N, Chandrasekaran M, Rasheed MH, Suresh RV \& Sivaprakash S. Evaluation of bone mineral density in thyrotoxicosis. Singapore Medical Journal 200647 947-950.

9 Cummings SR, Nevitt MC, Browner WS, Stone K, Fox KM, Ensrud KE, Cauley J, Black D \& Vogt TM. Risk factors for hip fracture in white women. New England Journal of Medicine 1995 $332767-773$.

10 Wejda B, Hintze G, Katschinski B, Olbricht T \& Benker G. Hip fractures and the thyroid: a case-control study. Journal of Internal Medicine 1995237 241-247.

11 Seeley DG, Kelsey J, Jergas M \& Nevitt MC. Predictors of ankle and foot fractures in older women. Journal of Bone and Mineral Research 199611 1347-1355.

12 Bauer DC, Ettinger B, Nevitt MC \& Stone KL. Risk for fracture in women with low serum levels of thyroid-stimulating hormone. Annals of Internal Medicine 2001134 561-568.

13 Ahmed LA, Schirmer H, Berntsen GK, Fonnebo V \& Joakimsen RM. Self-reported diseases and the risk of non-vertebral fractures: the Tromsø study. Osteoporosis International 2006 17 46-53.

14 Kim DJ, Khang YH, Koh J-M, Shong YK \& Kim GS. Low normal TSH levels are associated with low bone mineral density in healthy postmenopausal women. Clinical Endocrinology 2006 64 86-90.

15 Morris MS. The association between serum thyroid-stimulating hormone in its reference range and bone status in postmenopausal American women. Bone 200740 1128-1134.

16 Vestergaard P, Weeke J, Hoeck HC, Nielsen HK, Rungby J, Rejnmark L, Laurberg P \& Mosekilde L. Fractures in patients with primary idiopathic hypothyroidism. Thyroid 200010 335-340.

17 Vestergaard P, Rejnmark L \& Mosekilde L. Influence of hyper- and hypothyroidism, and the effects of treatment with antithyroid drugs and levothyroxine on fracture risk. Calcified Tissue International 200577 139-144.

18 Holmen J, Midthjell K, Krüger Ø, Langhammer A, Holmen TL, Bratberg GH, Vatten L \& Lund-Larsen PG. The Nord-Trøndelag Health study 1995-97 (HUNT 2): objectives, contents, methods and participation. Norsk Epidemiologi 200313 19-32.

19 Bjøro T, Holmen J, Krüger Ø, Midthjell K, Hunstad K, Schreiner T, Sandnes L \& Brochmann H. Prevalence of thyroid disease, thyroid dysfunction and thyroid peroxidase antibodies in a large, unselected population. The Health Study of Nord-Trøndelag (HUNT). European Journal of Endocrinology 2000143 639-647.

20 Berntsen GKR, Tollan A, Magnus JH, Søgaard AJ, Ringberg T \& Fønnebø V. The Tromsø Study: artifacts in forearm bone densitometry - prevalence and effect. Osteoporosis International $199910425-432$.

21 Greendale GA, Lee NP \& Arriola ER. The menopause. Lancet 1999 $353571-580$.

22 Surks MI, Goswami G \& Daniels SH. Controversy in clinical endocrinology. The thyrotropin reference range should remain unchanged. Journal of Clinical Endocrinology and Metabolism 2005 90 5489-5496.

23 Orimo H, Sugioka Y, Fukunaga M, Muto Y, Hotokebuchi T, Gorai I, Nakamura T, Kushida K, Tanaka H, Ikai T \& Oh-Hashi Y. Diagnostic criteria for primary osteoporosis. The Committee of the Japanese Society for bone and mineral research for development of diagnostic criteria of osteoporosis. Journal of Bone and Mineral Metabolism 199816 139-150.

24 Kanis JA \& Gluer CC. An update on the diagnosis and assessment of osteoporosis with densitometry. Committee of Scientific Advisors, International Osteoporosis Foundation. Osteoporosis International 200011 192-202.
25 von Recklinghausen FC. Die Fibrose oder deformierende Ostitis, die Osteomalazie und die osteoplastische Karzinose in ihren gegeseitigen Beziehungen. In Festschrift Rudolph Virchow, pp 1-89. Berlin: Reiner G, 1891.

26 Abe E, Marians RC, Yu W, Wu X-B, Ando T, Li Y, Iqbal J, Eldeiry L, Rajendren G, Blair HC, Davies TF \& Zaidi M. TSH is a negative regulator of skeletal remodelling. Cell 2003115 151-162.

27 Mazziotti G, Sorvillo F, Piscopo M, Cioffi M, Pilla P, Biondi B, Iorio S, Giustina A, Amato G \& Carella C. Recombinant human TSH modulates in vivo C-telopeptides of type-1 collagen and bone alkaline phosphatase, but not osteoprotegerin production in postmenopausal women monitored for differentiated thyroid carcinoma. Journal of Bone and Mineral Research 200520 480-486.

28 Sampath TK, Simic P, Sendak R, Draca N, Bowe AE, O’Brian S, Schiavi SC, McPherson JM \& Vukicivic S. Thyroid-stimulating hormone restores bone volume, microarchitecture, and strength in aged ovariectomized rats. Journal of Bone and Mineral Research 200722 849-859.

29 Sun J. Vukicevic S, Beliram R, Yang G, Sendak R, McPherson J, Zhu L-L, Iqbal J, Latif R, Natrajan A, Arabi A, Yamoah K, Moonga BS, Gabet Y, Davies TF, Bab I, Abe E, Sampath K \& Zaidi M. Intermittent recombinant TSH injections prevent ovariectomyinduced bone loss. PNAS 2008105 42889-44294.

30 Hase H, Ando T, Eldeiry L, Brebene A, Peng Y, Liu L, Amano H, Davies TF, Sun L, Zaidi M \& Abe E. TNF $\alpha$ mediates the skeletal effects of thyroid-stimulating hormone. PNAS 2006103 12849-12854.

31 Heemstra KA, van der Deure WM, Peeters RP, Hamdy NA, Stokkel MP, Corssmit EP, Romijn JA, Visser TJ \& Smit JW. Thyroid hormone independent associations between serum TSH levels and indicators of bone turnover in cured patients with differentiated thyroid carcinoma. European Journal of Endocrinology 2008159 69-76.

32 Surks MI, Ortiz E, Daniels GH, Sawin CT, Col NF, Cobin RH, Franklyn JA, Hershman JM, Burman KD, Denke MA, Gorman C, Cooper RS \& Weissman NJ. Subclinical thyroid disease: scientific review and guidelines for diagnosis and management. Journal of the American Medical Association 2004291 228-238.

33 Lee WY, Oh KW, Rhee EJ, Jung CH, Kim SW, Yun EJ, Tae HJ, Baek KH, Kang MI, Choi MG, Yoo HJ \& Park SW. Relationship between subclinical thyroid dysfunction and femoral neck bone mineral density in women. Archives of Medical Research 200637 511-516.

34 Grimnes G, Emaus N, Joakimsen R, Figenschau Y \& Jorde R. The relationship between serum TSH and bone mineral density in men and postmenopausal women: the Tromsø study. Thyroid 200818 1147-1155.

35 Rosen CJ \& Adler RA. Longitudinal changes in lumbar bone mineral density among thyrotoxic patients after attainment of euthyroidism. Journal of Clinical Endocrinology and Metabolism 199275 1531-1534.

36 Grant DJ, McMurdo MET, Mole PA \& Paterson CR. Is previous hyperthyroidism still a risk factor for osteoporosis in postmenopausal women? Clinical Endocrinology 199543 339-345.

37 Langdahl BL, Loft AG, Eriksen EF, Mosekilde L \& Charles P. Bone mass, bone turnover, calcium homeostasis, and body composition in surgically radioiodine-treated former hyperthyroid patients. Thyroid 19966 169-175.

38 Langdahl BL, Loft AG, Eriksen EF, Mosekilde L \& Charles P. Bone mass, bone turnover, and calcium homeostasis in former hyperthyroid patients treated by combined medical therapy. Thyroid 19966 161-168.

39 Marshall D, Johnell J \& Wedel H. Meta-analysis of how well measures of bone mineral density predict occurrence of osteoporotic fracture. BMJ 1996312 1254-1259.

Received 8 July 2009

Accepted 9 August 2009 